Transportation Research Forum

Estimation of Satisfied Customers in Public Transport Systems: A New Methodological Approach Author(s): Maria Morfoulaki, Yannis Tyrinopoulos, and Georgia Aifadopoulou

Source: Journal of the Transportation Research Forum, Vol. 46, No. 1 (Spring 2007), pp. 63-72

Published by: Transportation Research Forum

Stable URL: http://www.trforum.org/journal

The Transportation Research Forum, founded in 1958, is an independent, nonprofit organization of transportation professionals who conduct, use, and benefit from research. Its purpose is to provide an impartial meeting ground for carriers, shippers, government officials, consultants, university researchers, suppliers, and others seeking exchange of information and ideas related to both passenger and freight transportation. More information on the Transportation Research Forum can be found on the Web at www.trforum.org. 


\title{
Estimation of Satisfied Customers in Public Transport Systems: A New Methodological Approach
}

\author{
by Maria Morfoulaki, Yannis Tyrinopoulos, and Georgia Aifadopoulou
}

This paper addresses quality considerations in public transportation systems and, in particular, the relation between quality of public transport service and customer satisfaction. Its aim is to provide insights into the factors that affect transit-rider satisfaction and to present a model to calculate the probability of customer satisfaction. The proposed model identifies the most important attributes of public transport service quality that can be used for service planning.

\section{INTRODUCTION}

The goal of transport research should not be limited to theoretical analysis but should include the development of practical tools that may improve the quality of peoples' mobility and their daily life. The improvement of public transport services through efficient service-quality management and benchmarking can be considered a big step towards achieving such a goal. Although quality monitoring and benchmarking of public transport services are two methods implemented largely in some European Union (EU) countries and North America, they are rather new to public transport systems of many countries such as Greece. In these countries, research is crucial to facilitate widespread use of quality monitoring and benchmarking by public transport operators in their daily work.

From the customer's viewpoint, quality is relative and depends upon the objectives, means and results. Benchmarking, on the other hand, is a dynamic comparison based on the idea of improvement and action. Both benchmarking and quality improvement are used in public transport systems. More particularly, a way to improve public transport quality using benchmarking is to identify customers' priorities and needs, measure customers' satisfaction using appropriate indices, use this feedback to evaluate relevant service parameters, and finally take measures to improve services provided to the customers.

Following this approach, a customer satisfaction survey was conducted in the metropolitan area of Thessaloniki, Greece, to assess public transport services. Passengers were asked to assess certain system-quality attributes in terms of the importance that each attribute has for overall service quality and the user's level of satisfaction with that attribute. Through this survey, necessary quality-of-service data were collected and used to develop composite factors. Using the composite factors and information about the operational characteristics of the transit system in Thessaloniki, a multinomial logistic model was developed and estimated to provide some understanding of the factors contributing to the overall satisfaction level of customers with public transport service.

The rest of the paper is divided into four parts. The first deals with general principles regarding service quality and customer satisfaction in public transport. The second deals with the methodology. The third presents the results. The fourth presents the conclusions.

\section{DEFINING AND MEASURING QUALITY OF PUBLIC TRANSPORT SERVICE AND CUSTOMER SATISFACTION}

Quality in public transport service can be examined from the suppliers' and customers' viewpoints. In the first place, quality of service in public transport reflects passengers' perception of transit 


\section{Satisfied Customers}

service performance. The performance measures used to describe this perception are different from both the economic performance measures and the vehicle-based performance measures used in various manuals, such as the Transit Capacity and Quality of Service Manual (Hunte-Zaworski 2004). On the other hand, quality of service depends to a great extent, on the operating decisions made by the managers of a transit system given their budget constraints, the level of service to be provided, the characteristics of the areas to be served, and others. In this context, quality of service can also represent and measure how successful an agency is in meeting customer demands, i.e., customer satisfaction.

Customer satisfaction is the overall level of attainment of a customer's expectations. It is measured as the percentage of customer expectations which has actually been fulfilled. To measure and assess service quality from customers' viewpoint it is necessary to employ benchmarks that allow comparisons to be made. This comparison can be for quality in different time frames or at the same time among different routes or even among different operators. Because benchmarking can mainly provide values on an arithmetic scale, say from 1 to 10, the correspondence of the values on this scale to customer expectations is quite important. Knowledge, therefore, of how the expected value compares to the ideal value is necessary. What, in fact, is measured by this type of benchmarking is the existing gap between perceived and expected service as well as between expected and ideal service.

Recent research in the European Union indicated that both benchmarking and quality management are priorities in public transport. Many research projects, such as BENCHMARKING, EQUIP, and QUATTRO, have dealt with these and similar issues and reached some very interesting conclusions (European Union RTD Programme 1998, 2000, 2003). AFNOR, the French Organization for Standardization, provides the so-called quality loop (Morpace International Inc. and Cambridge Systematics Inc. 1997) shown in Figure 1. This figure shows the relationship between the perceived, expected, targeted, and delivered quality of services. The first two services pertain to the customers' side and the other two to the operator's (supplier's) side. The loop results from a series of interactions between the elements in it, thus creating four distinct gaps. The larger the gap between two successive elements of the loop, the greater the problem is in the particular public transport service or system. Improving service efficiency and quality means closing the four gaps.

Figure 1: Quality Loop at the Level of the Public Transportation System

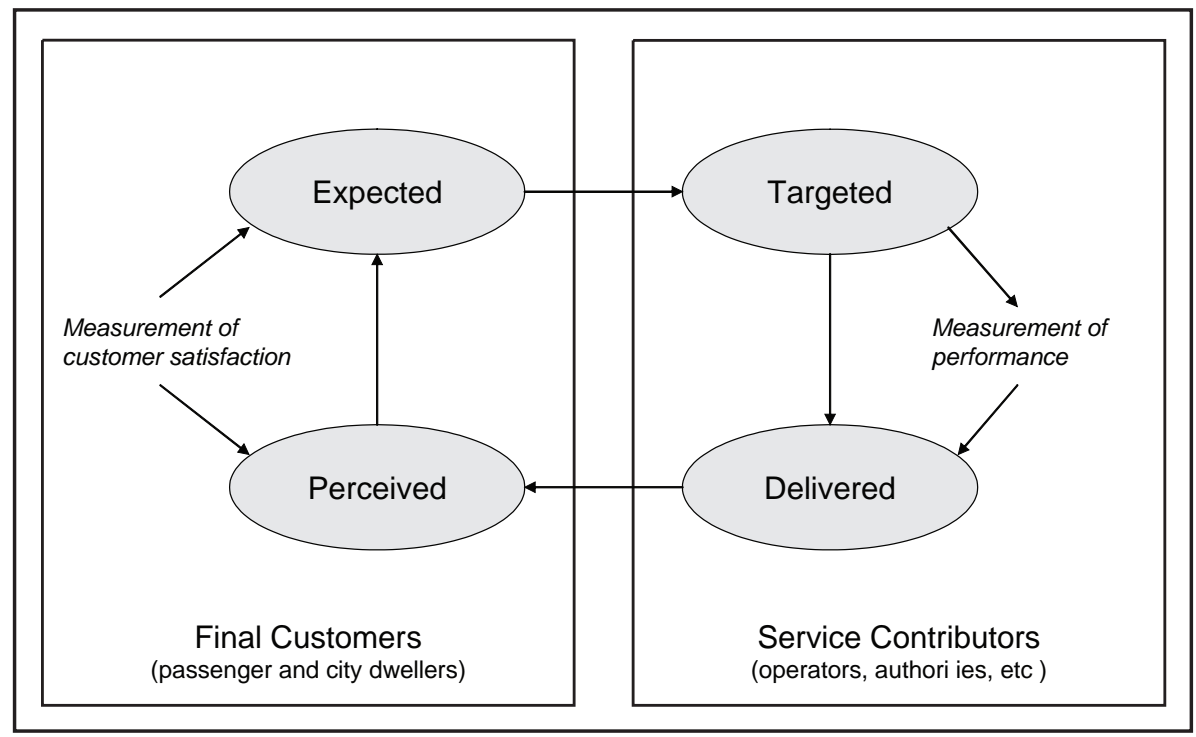

Source: European Union, 1998 
Another approach is found in the US Handbook for Measuring Customer Satisfaction and Service Quality in public transport (Morpace International Inc. and Cambridge Systematics Inc. 1997). This handbook identifies, in a similar way, five service gaps as follows: consumer expectations-management perception gap, management perception-service quality specifications gap, service quality specifications-service delivery gap, service delivery-external communications gap, expected-perceived service gap. The two approaches are quite similar and set the framework within which quality of public transport service can be measured and assessed.

Customer loyalty is a closely associated element of quality in public transport and is one of the main parameters examined in customer satisfaction surveys. According to the above handbook, customer loyalty is reflected in a combination of attitudes and behaviors and it is usually driven by customer satisfaction. It involves a commitment on the part of the customer to make a sustained investment in an ongoing relationship with transit service. Attitudes and behavior that are associated with customer loyalty include an intention to use transit service again; a willingness (often eagerness) to recommend the service to friends, associates, and other persons; and a commitment to, and even identification with, transit service. They also include disinterest in and or a general resistance to

Figure 2: Secure Customer Index

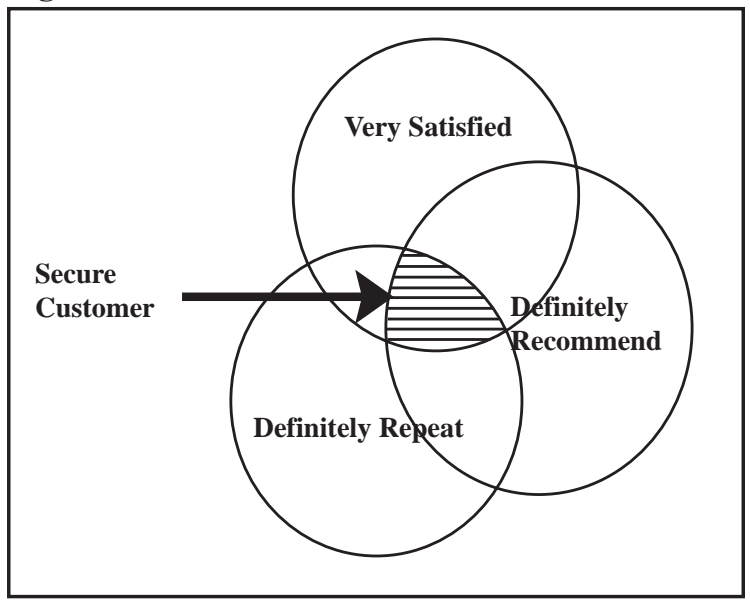

Source: Morpace International Inc. and Cambridge Systematics Inc,. 1999 alternative means of transportation, when these are available.

One measure of customer loyalty is the secure customer index (SCI). A secure customer is one who is very satisfied with the service and who will definitely continue to use it in the future, and would definitely recommend it to others. This definition is in Figure 2. The capacity to establish linkages between customer satisfaction, customer loyalty and business results should be a part of the methodology of any organization's customer-satisfaction measurement process.

On the implementation side, customer-satisfaction measurement or benchmarking is achieved through special surveys. The design of such a survey is a critical phase of any customer satisfaction

research process. Although initially mentioned in Elmore-Yalch (1998), recently there has been considerable discussion in the public transit literature regarding the best way to measure customer expectations and performance evaluations. Here, the European Committee for Standardization (2002) offers a comprehensive framework for analyzing both functional and technical quality determinants in urban public transport. This framework also serves as a common European reference to identify quality elements in public transport. In this framework, urban public transport attributes have been classified into eight categories (availability, accessibility, information, time, customer care, comfort, security and environment) and each category includes a number of quality characteristics.

\section{METHODOLOGY}

\section{The Study Area}

The study area includes the urban and suburban area of the city of Thessaloniki, Greece, also known as the Greater Thessaloniki Area (GTA). Thessaloniki is in the region of Central Macedonia, in the northern part of Greece, covering an area of $235 \mathrm{Km}^{2}$. It is the second-largest city in Greece with a population of approximately 1,200,000 and a work force of 380,000. GTA consists of the City of 
Thessaloniki and 17 other municipalities. The area is served by a private bus operator (Thessaloniki Urban Transport Organization), which operates under a concession contract with the Greek Ministry of Transport. The public transport operation is regulated and monitored by Thessaloniki Transport Authority, under the jurisdiction of the Ministry for Transport. The total person trips served within the GTA on a typical working day (1999 estimate) is 1.6 million.

\section{Data Collection Considerations}

The assessment of public transport service performance and quality in the above-mentioned study area was done in two ways. First, a customer satisfaction survey was conducted to collect information on a number of service quality attributes (parameters). The list of attributes is largely from Morpace International Inc. and Cambridge Systematics Inc. (1997) with some adjustments to reflect conditions in the study area and the peculiar characteristics of the local transit system. Twenty attributes were finally selected and cover a wide range of public transport service characteristics. They include accessibility, safety, on-time performance, information provision, ticketing, frequency and many others. For each attribute, respondents were asked to rate the overall quality of the public transport service, their levels of satisfaction with that attribute and its level of importance using a Likert scale.

The sampling procedure was carefully designed, taking into account the spatial distribution of the population and the minimum sample per geographic area. A structured sample of 400 passengers was used for the study. Furthermore, at least 20-30 passengers per group of adjacent municipalities and/or municipal departments participated in the survey to make the study inclusive of the region's population. Second, operational attributes of the local transportation system were measured through on-site surveys to assess the transit system's operational performance. These attributes involved vehicle load, average passenger waiting time at terminals and stops, on-time performance, average line speed and others. The onsite surveys were conducted in six terminals, covering $78 \%$ of the total journeys in the city, at 33 bus stops (3\% of the total) and on 25 lines (36.8\% of total transit lines). Of the 400 respondents to the survey, $61.7 \%$ were female, $26.6 \%$ were between 19 and 23 years old, $27.7 \%$ were students and $32.1 \%$ were employees. About $38.1 \%$ used the transportation services for their work and $28 \%$ for educational purposes. Finally, $63.2 \%$ were daily users of the public transportation system.

\section{Analytical Methods}

Factor Analysis. The analysis was done in two phases. In the first phase, principal component factor analysis was performed to identify the common factors underlying passengers' ratings of the quality indicators of satisfaction. When conducting factor analysis, an important issue is to examine the correlation between variables. If a variable is not correlated with any other, or with very few, it should be excluded from the factor analysis process. Although mild correlations of variables are not a problem in factor analysis, it is important to avoid extreme correlation and singularity. Multicolinearity was checked by examining the determinant of the correlation matrix. If the determinant was less than 0.00001, it was considered to exclude variables with very high correlation. The Kaiser-Meyer-Olkin (KMO) measure of sampling adequacy was used to compare the sizes of the observed correlation coefficients to the partial correlation coefficients. Large values of the KMO measure indicate that factor analysis of the variables is appropriate.

Another issue in factor analysis is the strength of the relationship between variables. This was examined by performing Bartlett's test of sphericity. This tests the null hypothesis that the variables in a correlation matrix are uncorrelated. When Bartlett's test is highly significant, factor analysis is appropriate. Finally, a measure of sampling adequacy (MSA) is applied to check the adequacy of each variable separately. A value of one for MSA indicates that it is appropriate to use a variable in the factor analysis. 
The criteria frequently used for determining the number of factors are the Kaiser criterion, Cattell scree plot, mean eigenvalues, variance explained criterion, and parallel analysis criterion. The Kaiser criterion and the Cattell scree plot were selected for identifying the number of factors that should be kept. The Kaiser criterion is a common rule of thumb for dropping the least important factors; the rule is to drop all components with eigenvalues under 1.0. Cattell scree test plots the components on the horizontal axis and the corresponding eigenvalues on the vertical axis. As the number of components increases the eigenvalues drop and their scree plot traces out a curve with an elbow as in Figure 3. Cattell's scree test says to drop all further components after the one starting the elbow.

\section{Figure 3: Scree Plot of Factor Analysis}

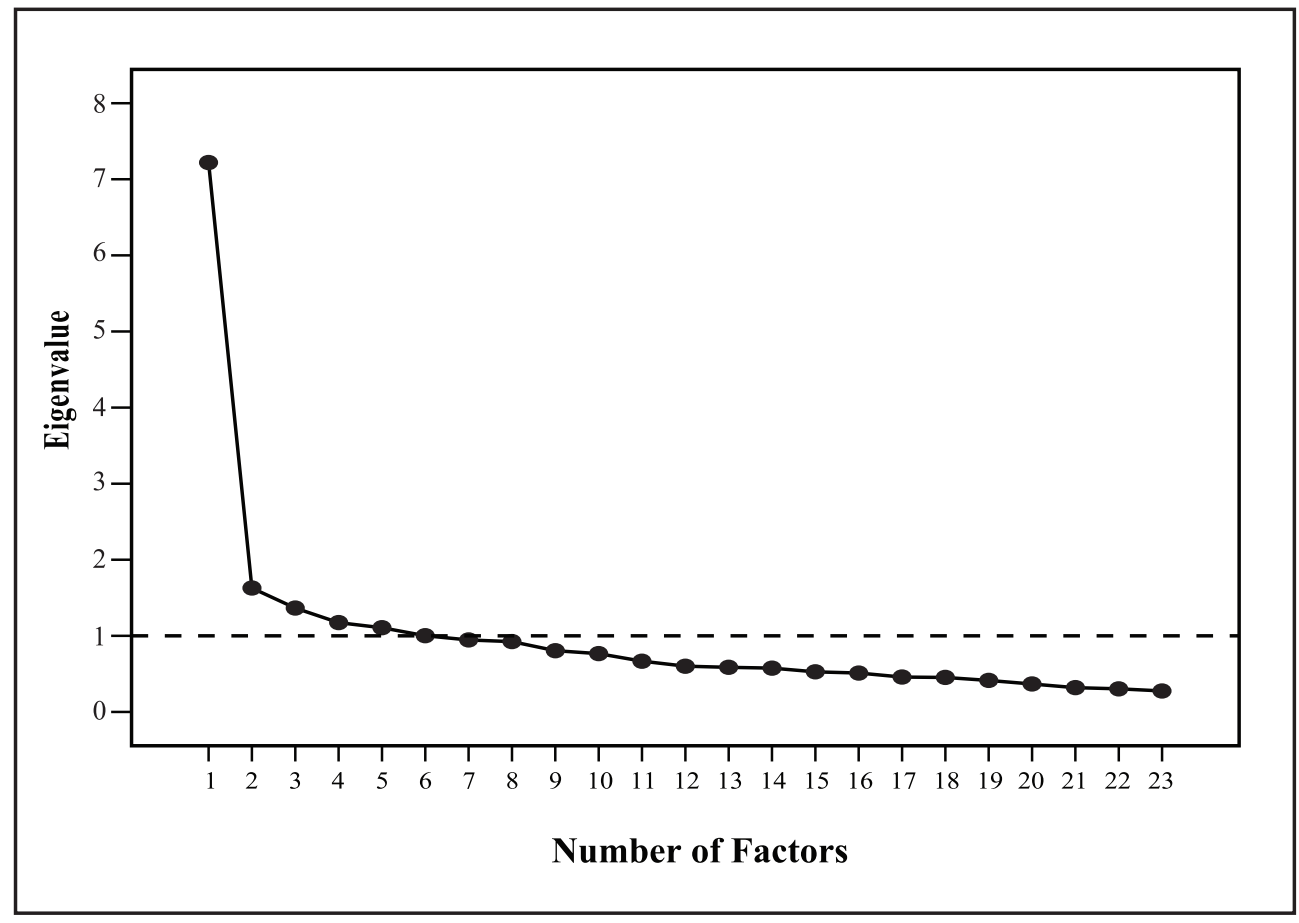

As a last step in the factor extraction process, the factors were rotated using orthogonal varimax rotation to facilitate factor interpretation and to produce uncorrelated factors. Factor rotation maximizes the loadings of each variable on one of the extracted factors, while minimizing the loading on all other factors. By this process, the factors and their associated variables were identified. Then, a factor score coefficient matrix was obtained and multiplied by the variables to obtain factor scores for each individual survey participant and for each factor. These factor scores were used in a logistic regression to explain the overall level of satisfaction of public transport passengers.

Multinomial logistic regression. In the survey, passengers expressed their overall satisfaction with the performance of transit services as a whole by choosing among the following alternative answers: very satisfied, satisfied, somewhat dissatisfied and very dissatisfied. These levels of satisfaction are the dependent variables in this study. Because they are categorical, a multinomial logistic regression model was estimated by maximum likelihood methods. The model estimates the probability of the occurrence of an event. The multinomial logistic regression model is expressed as:

$$
P_{n}(i)=\exp \left(\beta^{\prime} x_{i, n}\right) / \sum_{j \in C_{n}} \exp \left(\beta^{\prime} x_{j, n}\right)
$$


Where $\mathrm{x}_{\mathrm{i}, \mathrm{n}}$ and $\mathrm{x}_{\mathrm{j}, \mathrm{n}}$ are vectors describing the attributes of alternatives $\mathrm{i}$ and $\mathrm{j}, \beta$ is a coefficient vector and $P_{n}(i)$ is the probability that a user is satisfied at the level $n$. The fit of this model is assessed using a classification table showing correct and incorrect classification of the dependent variable, the likelihood ratio test and the chi-square test of goodness of fit measure (Pearson and deviance likelihood ratio). In this study, both the Pearson and deviance likelihood ratio are not significant, thus the proposed model has a good fit. Finally, the Wald statistic was used as an alternative test for assessing the significance of individual logistic regression coefficients.

\section{RESULTS}

\section{Factor Analysis Results}

The correlation matrix shows that the passenger ratings of the 20 service-quality indicators are correlated (some highly), because their correlations vary between 0.4 and 0.8 and are statistically significant at probability levels lower than 0.05 . Also there is multicolinearity because the value of the determinant of the correlation matrix is $5.271 \mathrm{E}-04$ and it is greater than the necessary value of 0.00001 . These results show that factor analysis is appropriate, and are also confirmed by the Bartlett's test of sphericity and the Kaiser-Meyer-Olkin (KMO) statistical tests. The KMO test is 0.904 while Bartlett's test is highly significant $(\mathrm{p}<0.001$, approximate chi-Square $=3032.880$, degrees of freedom $=253$ ). Additionally, the sampling adequacy test, ranged from 0.815 to 0.950 .

According to the factor analysis results, five factors account for $61.33 \%$ of the variance shared by the 20 variables. The eigenvalues and the percentage of variance accounted for by these five factors are 7.147 (35.73\%), 1.736 (8.68\%), 1.349 (6.74\%), 1.120 (5.59\%) and 1.090 (5.45\%) respectively. This result is confirmed by the Cattell scree plot presented in Figure 3. After rotation, the first factor accounted for $14.75 \%$ of the variance, the second accounted for $14.2 \%$ of additional variability and the other three factors accounted for $12.8 \%, 12.11 \%$ and $7.47 \%$ of the total variance respectively. The factor scores coefficient matrix is given in Table 1. A closer look at these scores reveals that the composite factors can be described as "waiting time," "circumstances on board," "frequency and on-time performance," "ticketing policy,” and "safety at passenger terminals.”

\section{Multinomial Logistic Regression Model}

The model developed for estimating passenger satisfaction uses the five composite factors derived from the factor analysis and some operational indicators of the transit system as independent variables. The initial quality indicators were not used because of their high correlation with each other. Because there are multiple categories of the dependent variable it was necessary to choose a base category as a comparison group. The last level of satisfaction category "very dissatisfied" was selected as a base category. The results of the multinomial logistic regression analysis are presented in Tables 2, 3, and 4.

Based on the Wald statistics in Table 2, the significant independent variables in the model are waiting time, circumstances on board, frequency and on-time performance, ticketing policy, and maximum vehicle load. The column labelled $\operatorname{Exp}(B)$ in Table 2 presents the odds ratio, which shows the strength of association between the predictors and the dependent variable. An odds ratio greater than one indicates that it is more likely to find very satisfied customers compared to finding very dissatisfied customers for a marginal increase in an independent variable. From the odds ratios, it is concluded that a unit increase in "satisfaction about waiting time" will increase the ratio of the probability of having a very satisfied customer versus the probability of having very dissatisfied customers by 70 times. A unit increase in the "circumstances-on-board" factor will increase the odds ratio of a very satisfied customer to not very satisfied customers by 68 times. On the other hand, there is no evidence that average vehicle speed affects the odds of finding a very satisfied customer. The odds ratio of this predictor is less than one and shows that an increase in average vehicle speed 
Table 1: Factor Scores Coefficient Matrix

\begin{tabular}{lccccc}
\hline & \multicolumn{7}{c}{ Factors } \\
& 1 & 2 & 3 & 4 & 5 \\
\hline Lines frequency & 0.0153 & 0.0000 & $\mathbf{0 . 2 8 9 7}$ & 0.0048 & 0.0012 \\
On-time performance & 0.0268 & 0.0063 & $\mathbf{0 . 2 4 6 4}$ & 0.0127 & 0.0003 \\
Service provision hours & 0.0190 & 0.1584 & $\mathbf{0 . 1 6 5 0}$ & 0.0057 & 0.0997 \\
Network coverage & 0.0001 & 0.0002 & $\mathbf{0 . 1 7 3 6}$ & 0.0002 & 0.0347 \\
Information provision about tickets and cards & 0.0206 & 0.0104 & 0.0069 & $\mathbf{0 . 1 5 3 9}$ & 0.0030 \\
Types of tickets and cards & 0.0075 & 0.0201 & 0.0108 & $\mathbf{0 . 2 6 5 7}$ & 0.0018 \\
Prices of tickets and cards & 0.0305 & 0.0233 & 0.0064 & $\mathbf{0 . 2 6 4 8}$ & 0.0835 \\
Tickets selling network and validation machines & 0.0026 & 0.0018 & 0.0178 & $\mathbf{0 . 1 4 7 1}$ & 0.0029 \\
Personnel behavior & 0.0198 & $\mathbf{0 . 1 7 3 1}$ & 0.0028 & 0.0047 & 0.0176 \\
Walking distance to terminals and bus stops & $\mathbf{0 . 0 4 2 9}$ & 0.0038 & 0.0063 & 0.0136 & 0.0292 \\
Information provision & 0.0199 & 0.0075 & 0.0091 & 0.0096 & $\mathbf{0 . 0 6 3 0}$ \\
Conditions at the terminals and bus stops, & 0.0017 & 0.0053 & 0.0042 & 0.0060 & $\mathbf{0 . 1 5 4 4}$ \\
Safety at the terminals and bus stops, & 0.0198 & 0.0001 & 0.0029 & 0.0068 & $\mathbf{0 . 4 8 1 7}$ \\
Onboard conditions & 0.0151 & $\mathbf{0 . 0 6 8 6}$ & 0.0021 & 0.0211 & 0.0129 \\
Vehicles cleanliness & 0.0281 & $\mathbf{0 . 2 0 8 7}$ & 0.0011 & 0.0227 & 0.0018 \\
Driving behavior & 0.0139 & $\mathbf{0 . 1 9 2 7}$ & 0.0006 & 0.0073 & 0.0002 \\
Onboard information provision & 0.0031 & $\mathbf{0 . 0 5 6 5}$ & 0.0413 & 0.0091 & 0.0036 \\
Distance between interchange points & $\mathbf{0 . 2 5 0 9}$ & 0.0189 & 0.0033 & 0.0243 & 0.0000 \\
Waiting time at interchange points & $\mathbf{0 . 2 6 5 3}$ & 0.0168 & 0.0003 & 0.0195 & 0.0085 \\
Information provision at interchange points & $\mathbf{0 . 1 9 7 3}$ & 0.0276 & 0.0091 & 0.0004 & 0.0000 \\
Extraction Method: Principal Component Analysis & & & & & \\
Rotation Method: Varimax with Kaiser Normalization & & & & & \\
\hline
\end{tabular}

would decrease the odds of finding a very satisfied customer. This may be because passengers want to travel more safely than quickly. The factor with the largest odds ratio is "ticketing policy." A unit increase in the "ticketing policy factor" when all other variables are controlled increases the odds ratio by 284 times. A better ticketing policy including better price, flexible ticket types, and an extensive ticket selling network increases the odds of very satisfied customers of public transport. Additionally, a unit increase in the "frequency and on-time performance" factor, when other variables are controlled will increase the odds of having very satisfied customers against not satisfied customers by 5.9 times. An explanation for the insignificant independent variables in the table may be the fact that the value of one is included in the $95 \%$ confidence interval around odds ratio. This shows that a change in the value of any of these independent variables is not associated with the dependent variable assuming a given value. Thus, the independent variable is not a useful predictor in the model.

To further facilitate model interpretation, the Nagelkerke's R-square index was calculated. This is a modification of the Cox and Snell coefficient to assure that the index can vary from 0 to 1 . The Nagelkerke's R-square showed that the model explains $62.4 \%$ of the total variation in the data (as shown in Table 3). In Table 4 the model correctly classifies $66 \%$ of all passengers, $68.2 \%$ of those who are very satisfied, $64.8 \%$ of satisfied passengers and $70.8 \%$ of very dissatisfied customers. Finally, the likelihood ratio test shows that the service-quality measures are more significant than the frequency and on-time performance factor in predicting satisfied customers. In general, an increase in the values of the composite measures will result in an increase of satisfied customers. 
Table 2: Multinomial Logistic Regression Model: Very Satisfied Customers

\begin{tabular}{|c|c|c|c|c|c|c|c|c|}
\hline \multicolumn{9}{|c|}{ Parameter Estimates } \\
\hline \multicolumn{2}{|c|}{ Satisfaction index } & \multirow[t]{2}{*}{ B } & \multirow[t]{2}{*}{$\begin{array}{l}\text { Standard } \\
\text { Error }\end{array}$} & \multirow[t]{2}{*}{ Wald } & \multirow[t]{2}{*}{ Significance } & \multirow[t]{2}{*}{$\operatorname{Exp}(B)$} & \multicolumn{2}{|c|}{$\begin{array}{l}\text { 95\% Confidence } \\
\text { Interval for } \\
\operatorname{Exp}(\mathrm{B})\end{array}$} \\
\hline & & & & & & & $\begin{array}{l}\text { Lower } \\
\text { Bound }\end{array}$ & $\begin{array}{l}\text { Upper } \\
\text { Bound }\end{array}$ \\
\hline \multirow[t]{13}{*}{$\begin{array}{l}\text { Very } \\
\text { satisfied }\end{array}$} & Intercept & -1.893 & 23.141 & 0.007 & 0.935 & & & \\
\hline & Waiting Time & 4.255 & 1.094 & 15.125 & 0.000 & 70.456 & 8.253 & 601.4 \\
\hline & $\begin{array}{l}\text { Circumstances on } \\
\text { board }\end{array}$ & 4.226 & 0.887 & 22.698 & 0.000 & 68.429 & 12.029 & 389.2 \\
\hline & $\begin{array}{l}\text { Frequency and on- } \\
\text { time performance }\end{array}$ & 1.764 & 0.605 & 8.512 & 0.004 & 5.838 & 1.784 & 19.098 \\
\hline & Ticketing policy & 5.648 & 1.092 & 26.762 & 0.000 & 284 & 33.382 & 2410 \\
\hline & Terminal safety & 0.501 & 0.567 & 0.780 & 0.377 & 1.650 & 0.543 & 5.012 \\
\hline & $\begin{array}{l}\text { Average vehicle } \\
\text { load }\end{array}$ & -0.325 & 0.233 & 1.949 & 0.163 & 0.723 & 0.458 & 1.140 \\
\hline & $\begin{array}{l}\text { Maximum vehicle } \\
\text { load }\end{array}$ & 0.441 & 0.209 & 4.457 & 0.035 & 1.554 & 1.032 & 2.341 \\
\hline & $\begin{array}{l}\text { Average speed of } \\
\text { vehicles }\end{array}$ & -0.285 & 0.178 & 2.577 & 0.108 & 0.752 & 0.530 & 1.065 \\
\hline & Journey run time & .0030 & 0.167 & 0.032 & 0.859 & 1.030 & 0.743 & 1.429 \\
\hline & $\begin{array}{l}\text { Mean waiting of } \\
\text { passengers at stop } \\
\text { points }\end{array}$ & 1.791 & 1.031 & 3.016 & 0.082 & 5.994 & 0.794 & 45.220 \\
\hline & $\begin{array}{l}\text { Mean waiting } \\
\text { time of passengers } \\
\text { at terminal } \\
\text { stations }\end{array}$ & -1.042 & 1.010 & 1.063 & 0.303 & 0.353 & 0.049 & 2.556 \\
\hline & Reliability index & -0.125 & 0.252 & 0.245 & 0.621 & 0.883 & 0.539 & 1.447 \\
\hline
\end{tabular}


Table 3: Fit Statistics for Multinomial Logistic Regression Model

\begin{tabular}{|c|c|c|c|c|}
\hline \multicolumn{5}{|c|}{ Model Fitting Information } \\
\hline Model & -2 Log Likelihood & Chi-Square & $\begin{array}{r}\text { Degrees of } \\
\text { Freedom }\end{array}$ & Probability \\
\hline Intercept Only & 605.5150 & & & \\
\hline Final & 387.5510 & 217.9640 & 36 & 0.0000 \\
\hline \multicolumn{5}{|c|}{ Goodness-of-Fit } \\
\hline Pearson & & 460.7820 & 756 & 1.0000 \\
\hline Deviance & & 387.5510 & 756 & 1.0000 \\
\hline \multicolumn{5}{|c|}{ Pseudo R-Square } \\
\hline Cox and Snell & & 0.5610 & & \\
\hline Nagelkerke & & 0.6240 & & \\
\hline McFadden & & 0.3600 & & \\
\hline
\end{tabular}

The reference category is 'very dissatisfied'

Table 4: Classification Table for Multinomial Logistic Regression Model

\begin{tabular}{lrrrrr}
\hline & \multicolumn{5}{c}{ Predicted } \\
\cline { 2 - 6 } Observed & $\begin{array}{c}\text { Very } \\
\text { satisfied }\end{array}$ & Satisfied & $\begin{array}{c}\text { Somewhat } \\
\text { dissatisfied }\end{array}$ & $\begin{array}{c}\text { Very } \\
\text { dissatisfied }\end{array}$ & $\begin{array}{c}\text { Percent } \\
\text { Correct }\end{array}$ \\
\hline Very satisfied & 15 & 6 & 1 & 0 & $68.2 \%$ \\
Satisfied & 6 & 70 & 31 & 1 & $64.8 \%$ \\
Somewhat dissatisfied & 1 & 27 & 80 & 5 & $70.8 \%$ \\
Very dissatisfied & 0 & 1 & 11 & 10 & $45.5 \%$ \\
Overall percentage & $8.3 \%$ & $39.2 \%$ & $46.4 \%$ & $6.0 \%$ & $66.0 \%$ \\
\hline
\end{tabular}

\section{CONCLUDING REMARKS}

This paper identifies five basic quality factors that determine customer satisfaction with transit services using data for the public transit system in Thessaloniki, Greece. These factors are waiting time, circumstances on board vehicles, frequency and on-time performance, ticketing policy, and terminal safety. Using these factors, the paper develops a multinomial logistic model to estimate the probability of very satisfied customers. The results show that customer satisfaction can be improved by improving customer perception of waiting time, circumstances on board transit vehicles, frequency and on-time performance, and terminal safety. Public transport operators can use these factors to plan and implement actions to improve their customers' satisfaction with transit services. The approach described above may be applied to different sub-areas of public transport networks or to different bus lines (routes) or groups of bus routes. Different factors may be found to be significant in each area or group of routes, depending on passengers' characteristics and the servicequality attributese considered in each case as important.

With respect to the research in this paper, it needs mentioning that it covers a part only of the research required to better understand the relationships between customer satisfaction and public transport service quality. Additional research is definitely necessary. A positive point of this effort is that the approach followed and the tools employed can be used in other areas after a cautious adaptation. The findings, however, will always depend on the specific characteristics of the customers considered, customer expectations and preferences. 


\section{References}

Elmore-Yalch, R. TCRP Report 37, A Handbook: Integrating Market Research into Transit Management. Transportation Research Board, National Academy Press, Washington D.C., 1998.

European Committee for Standardization (CEN). Transportation-Logistics and Services - Public Passenger Transport - Service Quality Definition, Targeting and Measurement. Belgium, 2002.

European Union RTD Programme, Project EQUIP. Extending the Quality of Public Transport. Final Report and its Annex: Practical Handbook, 2000.

European Union RTD Programme, Project PORTAL. Promotion of Results in Transport Research and Learning. Final Report, Belgium, 2003.

European Union RTD Programme, Project QUATTRO. Quality Approach in Tendering/Contracting Urban Public Transport Operations. Final Report, Belgium, 1998.

Hunte-Zaworski. K. Transit Capacity and Quality of Service Manual. (2 ${ }^{\text {nd }}$ Edition). Transportation Research Board, National Academy Press, Washington D.C., 2004.

Morpace International Inc. and Cambridge Systematics Inc. A Handbook for Measuring Customer Satisfaction and Service Quality. Transportation Research Board. TCRP Report 47, National Academy Press, Washington D.C., 1997.

Maria Morfoulaki is a transportation engineer with experience in transportation planning models and public transport operational and quality issues. She obtained a Ph.D. in civil engineering from the Polytechnic School of the Aristotle University of Thessaloniki in 2004. She works at the Hellenic Institute of Transport (HIT), a part of the Center for Research and Technology Hellas (CERTH) as a transportation research associate.

Yannis Tyrinopoulos is a senior transportation planner with interests in the application of advanced Telematics systems to the transport sector, in particular public transport. He obtained a Ph.D. from the Polytechnic School of the Aristotle University of Thessaloniki. His current position is at the Hellenic Institute of Transport (HIT), a part of the Center for Research and Technology Hellas (CERTH).

Georgia Aifadopoulou is principal researcher in the Hellenic Institute of Transport. From 1995 to 2004 she was the managing director of TransEuropean Consulting Unit of Thessaloniki (TRUTh S.A.). She holds a Ph.D. in civil engineering from the Aristotle University of Thessaloniki. Her professional activities cover a wide range of studies relevant to traffic management and control, transport systems design, introduction of new technologies in urban road freight, and maritime transport. 